\title{
A novel mutation in the calcium-sensing receptor responsible for autosomal dominant hypocalcemia in a family with two uncommon parathyroid hormone polymorphisms
}

\author{
D Álvarez-Hernández, Í Santamaría, M Rodríguez-García, P Iglesias ${ }^{1}$, \\ R Delgado-Lillo ${ }^{2}$ and $\mathbf{J}$ B Cannata-Andía \\ Bone and Mineral Research Unit, Instituto Reina Sofía de Investigación, Hospital Universitario Central de Asturias, c/Julián Clavería s/n, \\ 33006 Oviedo, Spain \\ ${ }^{1}$ Endocrinology Unit, Hospital General de Segovia, Segovia, Spain \\ ${ }^{2}$ Nephrology Unit, Clinica Ruber, Madrid, Spain
}

(Requests for offprints should be addressed to Í Santamaría; Email: isr@ hca.es)

\begin{abstract}
A novel missense activating mutation in the extracellular calcium-sensing receptor (CaSR) is reported in this work. It was identified in three related subjects with the phenotypic features of autosomal dominant hypocalcemia $(\mathrm{ADH})$. The proband, a 27-year-old woman, diagnosed as having hypoparathyroidism at 7 years of age and a history of seizures, showed the highest penetrance of the mutation. The remaining two affected members presented asymptomatic chronic hypocalcemia despite severe hypoparathyroidism associated with high levels of serum phosphate and calcium urinary excretion. The missense mutation (Glu ${ }^{604}$ Lys) affected an amino acid residue in the $\mathrm{C}$ terminus of the cysteine-rich domain of the extracellular amino-terminal domain, which seems to be required for the coupling of ligand binding to the activation of intracellular signaling pathways. This genetic change cosegregated with hypocalcemia in all the individuals where the mutation was found. As parathyroid hormone (PTH) secretion is the regulatory target of the CaSR, polymorphism analysis of the PTH gene was carried out. PTH polymorphisms were analyzed in the kindred studied. Affected members for the Glu ${ }^{604}$ Lys CaSR mutation which also carried the uncommon PTH alleles showed higher penetrance of the mutation, with more severe autosomal dominant hypocalcemia. These results suggested that the PTH gene could act as a modifier locus of $\mathrm{ADH}$, affecting the penetrance of the activating CaSR mutation described.
\end{abstract}

Journal of Molecular Endocrinology (2003) 31, 255-262

\section{Introduction}

Autosomal dominant hypocalcemia $(\mathrm{ADH})$ is a rare hereditary syndrome characterized by low serum parathyroid hormone (PTH) levels despite hypocalcemia and relative hypercalciuria, leading to nephrolithiasis and nephrocalcinosis, especially after active vitamin D treatment (Winter et al. 1983, De Campo et al. 1988). Mutations responsible for a gain-of-function in the calcium-sensing receptor (CaSR) gene and able to inhibit PTH secretion and renal calcium reabsorption are the cause of $\mathrm{ADH}$
(Pollak et al. 1994, Baron et al. 1996). The clinical presentation of $\mathrm{ADH}$ varies from asymptomatic hypocalcemia to neonatal hypocalcemic seizures even in families with the same CaSR gene mutation.

The CaSR was first identified in bovine parathyroid cells and was later found to be expressed in the kidney and other tissues (Brown et al. 1995b). The human CaSR encodes a polypeptide of 1078 amino acids organized into three domains: a very large (612 amino acids) extracellular domain at the amino-terminus, a 
transmembrane domain with seven membranespanning helixes characteristic of $G$ proteincoupled receptors and an intracellular (216 amino acids) carboxyl-terminal tail (Brown et al. 1993, 1995a, Aida et al. 1995, Garrett et al. 1995, Brown 2000). Mutations in this CaSR involving loss of function cause familial benign hypercalcemia, also known as familial hypocalciuric hypercalcemia; those who have this autosomal disorder, generally asymptomatic, have life-long elevations of serum calcium concentrations, together with a low urinary excretion of calcium (Pollak et al. 1993). On the other hand, heterozygous gain-of-function (activating) mutations are associated with the reverse phenotype - autosomal dominant hypocalcemia as described previously. To date, 40 inactivating and 25 activating mutations have been identified (Hendy et al. 2000). These are mostly missense mutations, unevenly distributed throughout the coding region of the CaSR but clustered in two regions: within the first 300 amino acids of the extracellular domain and from amino acids 520 to 881 in or near the transmembrane domain. Residues in the first 300 amino acids of the extracellular domain have been shown to be important for calcium binding to the CaSR and/or dimerization of the receptor (Brauner-Osborne et al. 1999, Zhang et al. 2001).

PTH secretion is the regulatory target of the CaSR. Several polymorphisms have been described in the gene encoding PTH, which may influence not only the secretion rate of the hormone in response to the CaSR signaling but also the efficiency of the hormone, as has been shown in bone metabolism studies (Katsumata et al. 2002) and familial isolated hypoparathyroidism (FIH) (Miric \& Levine 1992). This syndrome, characterized by hypocalcemia and hyperphosphatemia due to an inherited deficient secretion of biologically active parathormone, has been related to PTH gene mutations and polymorphisms (Ahn et al. 1986, Sunthornthepvarakul et al. 1999). A mutation in the transcription factor GCMB has also been associated with FIH (Ding et al. 2001). Three major polymorphisms and two mutations have been described in the PTH gene; one of the polymorphisms is located in intron 1, only 15 nucleotides from the start codon (Yamamoto et al. 1997) whilst the remaining two are located in intron 2 and exon 3 (Mullersman et al. 1992). A mutation in the signal peptide of the preparathyroid hormone gene has

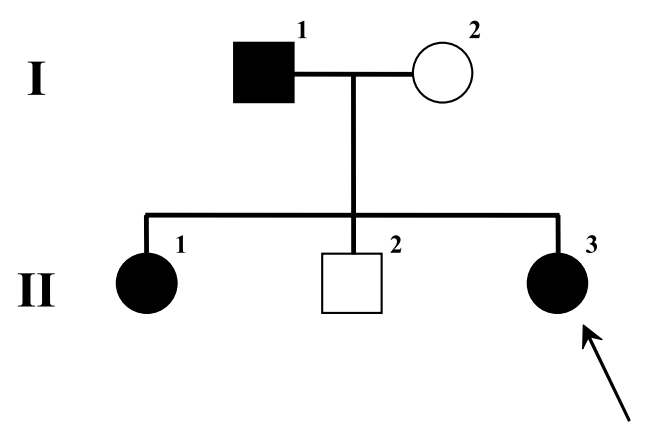

Figure 1 Pedigree of the studied kindred. The arrow indicates the proband. Solid symbols are individuals with the $\mathrm{Glu}^{604}$ Lys mutation.

also been described (Sunthornthepvarakul et al. 1999), along with a donor splice site mutation in the first nucleotide of intron 2 (Parkinson et al. 1993). Although all five genetic variations have been studied in relation to FIH syndrome, no conclusive general results have been defined, thus pointing out the variability of the causes of this condition (Ahn et al. 1986).

As previously stated, the penetrance of CaSRactivating mutations is extremely variable. To date, no relationship has been found either between activating changes and polymorphisms of the CaSR gene with pathological expression of the mutations (Kanazawa et al. 2000) or with the location of those changes within the CaSR gene (Nagase et al. 2002). In this work we report a novel activating mutation $\left(\mathrm{Glu}^{604} \mathrm{Lys}\right)$ in a Spanish kindred suffering autosomal dominant hypocalcemia that may be modulated by polymorphisms of the PTH gene and thus affecting its clinical presentation.

\section{Materials and methods}

\section{Clinical subjects}

The proband (subject II.3; Fig. 1) was born in 1976 and was diagnosed as having idiopatic hypoparathyroidism at 7 years of age after presenting with seizures. She has been clinically monitored to date. Studies were also conducted on the other four members of her family. The absence of the Glu ${ }^{604}$ Lys mutation was verified in 100 unrelated Spaniards by RFLP. The study was approved by the Hospital Universitario Central de Asturias Clinical Ethics Committee. 
Table 1 Oligonucleotides designed for the amplification and sequencing of the DNA fragments used in this work. Primers for the CaSR gene: in those coding regions too large to sequence in one row (exons 4 and 7 ) internal primers were designed for sequencing. Primers for the PTH gene are also shown

Location

Gene

CaSR

Exon 2

Exon 3

Exon 4

Exon 4-internal-1

Exon 4-internal-2

Exon 5

Exon 6

Exon 7

Exon 7-internal-1

Exon 7-internal-2

Exon 7-internal-3

PTH
Primers $\left(5^{\prime}\right.$ to $\left.3^{\prime}\right)$

Forward: CTGCAGGGAGTGAACTGCTCC Reverse: GTGGGGGCAATAAGCTTCAGCAT Forward: GGGCTCTGTACAGAGCATGCC Reverse: TGGTAAACCGTATGGCTATTGGG Forward: ACAGCCTGGAGGCTCACTCAG Reverse: TGCCTGGAGTTGCAGCCCAAC Forward: TCTCCAGTGGCCCAGATCTTGA Reverse: GTGGGGGCAATAAGCTTCAGCAT Forward: TAGCAACAGCTCGACAGCCTTC Reverse: GTGGGGGCAATAAGCTTCAGCAT Forward: GTGCAGGGCACAGCCTACCTA Reverse: TTCCTGCCCCTGGTGGAGACA Forward: GAAGAGACAGTAGGGCTGGCC Reverse: CCAGGCCTCCGAAGTGGACC Forward: GTCTGTGCCACACAATAACTCAC Reverse: CCAAGAAACCTCTCTGCATTCTC Forward: CTGCATCTCATGCATCCTGGTG Reverse: CCAAGAAACCTCTCTGCATTCTC Forward: TCATTCCAGCCTATGCCAGCAC Reverse: CCAAGAAACCTCTCTGCATTCTC Forward: AGCAGCAACGATCTCAGCAGCA Reverse: CCAAGAAACCTCTCTGCATTCTC

Forward: ATTAGTTAGTATTGCATTCTGT Reverse: AACAGTACTTACTTAACAGATT Forward: ATTAGTTAGTATTGCATTCTGT Reverse: TTGAATTAGCAGCATGTATTG

\section{Genomic DNA isolation}

High molecular weight nuclear DNA was isolated from peripheral blood leukocytes of the proband, the other four family members and 100 normal subjects by standard procedures (Sambrook et al. 1989).

\section{Amplification, sequence and confirmation of the CaSR mutation}

In the proband, all protein-coding exons (2-7) of the CaSR were amplified by PGR using the primer pairs detailed in Table 1. PCR was performed in 30 cycles using the following steps: denaturation at $95^{\circ} \mathrm{C}$ for $30 \mathrm{~s}$, annealing at $64{ }^{\circ} \mathrm{C}$ for $30 \mathrm{~s}$ and extension at $72{ }^{\circ} \mathrm{C}$ for $90 \mathrm{~s}$ on a volume of $20 \mu \mathrm{l}$. The PGR reactions were carried out in a GeneAmp 9700 PCR system from Applied
Biosystems (Foster City, CA, USA). The amplification products were purified and nucleotide sequences of both strands were determined by direct sequencing with an Applied Biosystems 310A automatic sequencer.

After finding the Glu ${ }^{604}$ Lys mutation in the proband, exon 7 of the CaSR gene of other family members and control subjects was amplified by PCR using the primer pair 5'-GTCTGTGG CACACAATAACTCAC-3' and 5'-CGAAGAAA CGTCTCTGGATTCTC-3'. As the mutation, a replacement of a guanine by an adenine, destroys a recognition site for TaqI (TGGA), this endonuclease was used to digest the amplified $431 \mathrm{bp}$ fragment. The absence of the mutation generates two fragments of 310 and $121 \mathrm{bp}$, detected by electrophoresis on a $1 \cdot 2 \%$ agarose gel (Fig. 2A). These experiments were carried out at least twice 


\section{\begin{tabular}{lllllll}
\hline I. 1 & I.2 & II. 1 & II. 2 & |I. 3
\end{tabular}}

A

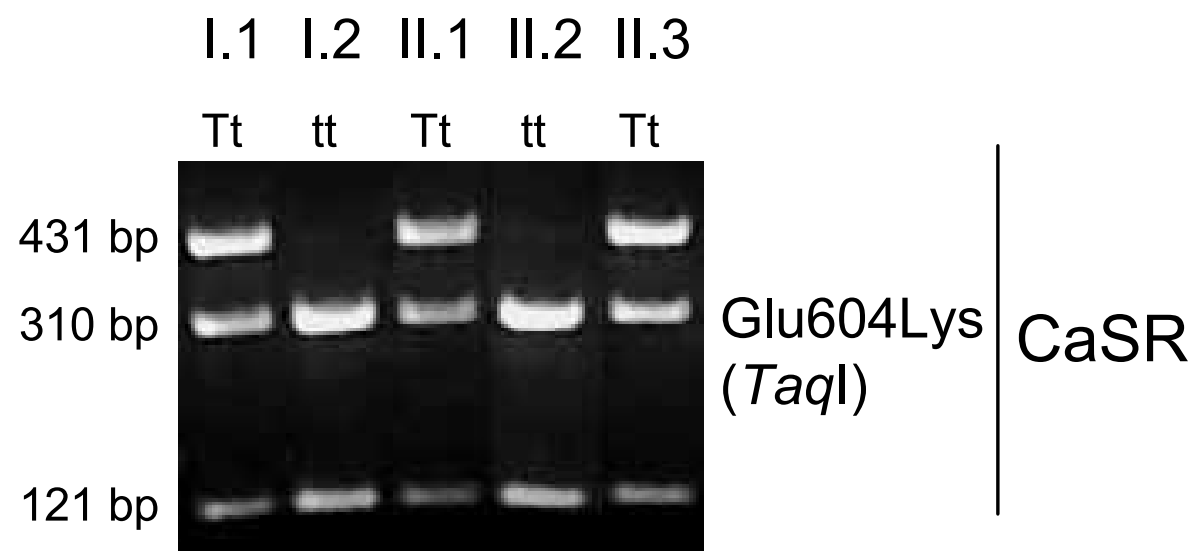

B

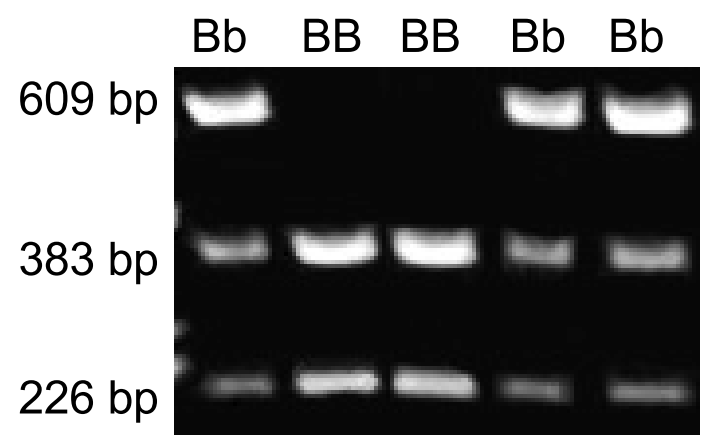

Bst BI

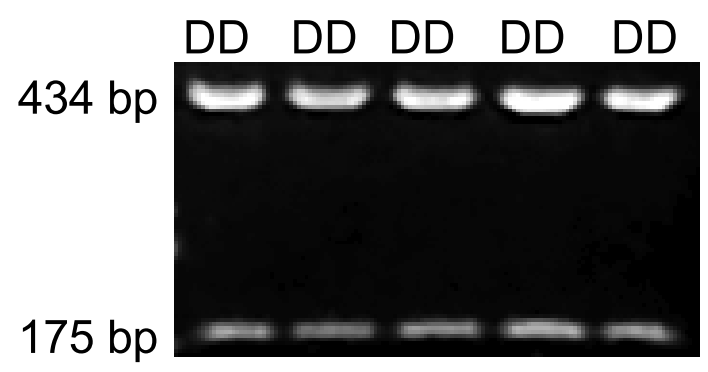

PTH

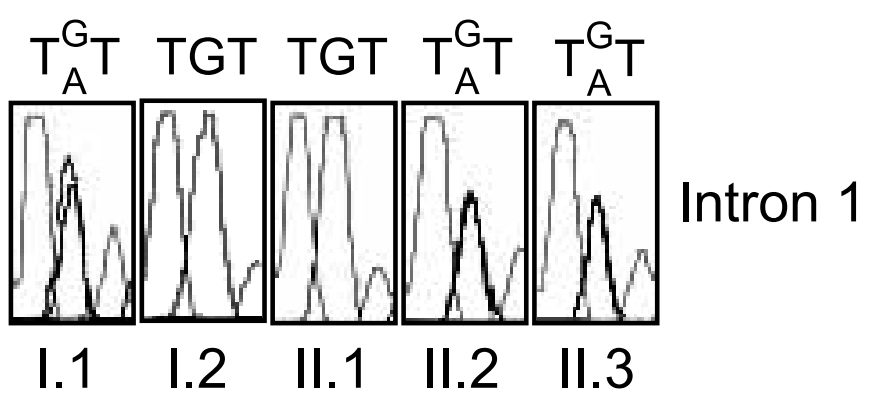


and the results were reproducible. Each experiment contained the affected patient's DNA which was heterozygous for the mutation to ensure that all samples were completely digested by restriction enzyme.

\section{PTH polymorphisms analysis}

PTH gene polymorphisms were studied by PCR amplification (primers reproduced in Table 1) and restriction or direct sequencing analysis was carried out in all the family members. PCR conditions were: denaturation at $95{ }^{\circ} \mathrm{C}$ for $30 \mathrm{~s}$, annealing at $54{ }^{\circ} \mathrm{C}$ for $15 \mathrm{~s}$ and extension at $72{ }^{\circ} \mathrm{C}$ for $30 \mathrm{~s}$ on a volume of $20 \mu \mathrm{l}$. All three polymorphisms described to date were analyzed. For intron 1 polymorphism, a $186 \mathrm{bp}$ DNA fragment was amplified and sequenced. The remaining two PTH gene polymorphisms, located in intron 2 and exon 3 disrupt restriction sites $B s t B \mathrm{I}$ and DraII respectively; they were determined by amplification of a $609 \mathrm{bp}$ fragment and restriction analysis with the appropriate enzymes. In the case of BstBI, the presence of the restriction site (denoted as $\mathrm{B}$ ) produces two DNA fragments of 383 and $226 \mathrm{bp}$, while the presence of the DraII restriction site (denoted as D) produces two fragments of 434 and $175 \mathrm{bp}$.

\section{Results}

DNA sequence analysis of the proband showed a heterozygous single base $\mathrm{G}-\mathrm{A}$ missense mutation in position 2182 of exon 7 (GenBank U20759), resulting in the amino acid substitution of a glutamic acid by a lysine. The mutation found (Glu $\left.{ }^{604} \mathrm{Lys}\right)$, lies at the $\mathrm{C}$ terminus of the Cys-rich domain of the extracellular head, only nine residues from the first transmembrane helix.

Once the mutation was found by sequencing the proband's coding regions of the CaSR gene, and taking into account that the $\mathrm{G}-\mathrm{A}$ transition destroys a TaqI recognizing sequence, this restriction site was used to analyze the other members of the family and 100 unrelated DNA controls. Figure $2 \mathrm{~A}$ shows that the mutation analysis of the CaSR found three affected members of the family that was studied: I.1, II.1 and the proband II.3. The results are thus consistent with the autosomal dominant inheritance pattern in ADH. None of the unrelated controls was positive for the genetic change, thus confirming its mutation character. Although members I.1 and II.3 were currently in treatment (being the only ones suspected of carrying the mutation), II.1 was also found to posses the genetic change in the CaSR gene. II.1 was undiagnosed, but the analytical results confirmed low calcium serum levels (calcium $6.5 \mathrm{mg} / \mathrm{dl}$ ), thus confirming the autosomal dominant hypocalcemia determined by the $\mathrm{Glu}^{604} \mathrm{Lys}$ change.

While I.1 and II.1 were asymptomatic, and only low levels of serum calcium and PTH have determined their medical treatment, II.3, on the other hand, was diagnosed with idiopatic hypoparathyroidism at 7 years of age after suffering tetanias caused by hypocalcemia (calcium $6 \mathrm{mg} / \mathrm{dl}$; intact PTH $($ iPTH $)<1 \mathrm{pg} / \mathrm{ml})$. Treatment with vitamin D produced a toxic hypercalcemia episode (calcium $15.7 \mathrm{mg} / \mathrm{dl}$ ), probably due to D3 hypervitaminosis. Lithotripsy was required to eliminate a calcium oxalate kidney stone at 14 years of age and a digestive hemorrhagic episode was treated at 19 years of age.

I.1 was diagnosed with hypocalcemia (calcium $6.5 \mathrm{mg} / \mathrm{dl}$; iPTH $6 \mathrm{pg} / \mathrm{ml}$ ) after a routine analysis at 54 years of age and has been on calcium, vitamin $\mathrm{D}$, magnesium, potassium and thiazyde treatment without an improvement in the calcemic levels. A review of his clinical records showed an isolated episode of loss of consciousness at 10 years of age, while lithiasis in both kidneys, along with calcification of his cerebral falx and several smooth tissues, are a good indication of a long and severe penetrance of the pathology.

II. 1 had remained undiagnosed until the genetic study showed the presence of the CaSR-activating

Figure 2 Genetic analysis of the proband's family. (A) Analysis of the Glu ${ }^{604}$ Lys mutation in all members of the family. The mutation destroys a Taql restriction site present in exon 7 of the CaSR gene. I.1, II.1 and II.3 are heterozygous for the mutation. (B) Analysis of the PTH polymorphisms. A 609 bp DNA fragment partially comprising intron 2 and exon 3 was amplified. Restriction analysis with BstBI and Drall is shown in the upper images, with uppercase letters $B$ and $D$ denoting presence of those restriction sites. For the intron 1 polymorphism, a 186 bp was amplified and sequenced. The partial sequence comprising the genetic change $(G$ to $A)$ is shown in the lower image. 
mutation. The biochemical parameters revealed hypocalcemia, low levels of serum PTH and hyperphosphatemia, but none of the related pathological consequences found in both his father and younger sister.

Neither I.2 nor II.2 showed any anomalies in their biochemical parameters. Both parents of I.1 are deceased and therefore unavailable for the mutation analysis, but as none had a history of hypocalcemia, it is possible to speculate that the CaSR dominant mutation appeared de novo in I. 1 .

In order to explain the differences in the clinical presentation among the affected members, a study of the PTH gene variations was performed. The results, shown in Fig. 2B, demonstrated that I.1, II.2 and II.3 presented variation for the polymorphism located 15 nucleotides from the initiation codon (intron 1) and for the BstBI restriction site. All family members were homozygous for the silent polymorphism located in the DraII site of exon 3. Analysis of the signal peptide of the preproparathyroid hormone gene and the donor splice site mutations was also carried out, showing that none of them were present in the kindred (data not shown).

\section{Discussion}

The present study demonstrates a novel missense activating mutation (Glu $\left.{ }^{604} \mathrm{Lys}\right)$ affecting the CaSR in a Spanish kindred with ADH. The proband has been suffering severe hypocalcemia and hypercalciuria since childhood, while the other affected members of this family showed asymptomatic hypocalcemia with hyperphosphatemia, relative hypercalciuria and low levels of PTH. As these results and the autosomal dominant pattern of inheritance are suggestive of $\mathrm{ADH}$, the molecular studies necessary to establish the diagnosis were conducted. The results suggested that the Glu ${ }^{604}$ Lys mutation caused ADH in this family, as the mutation was found in all three hypocalcemic members but in none of the normocalcemic members of the family or in 100 control subjects.

Interestingly, this mutation has also been recently described in an Australian kindred during the elaboration of this work (Tan et al. 2003). Functional analysis of the Glu ${ }^{604}$ Lys mutation confirmed that the mutation significantly increased the sensitivity to $\mathrm{Ca}^{2+}$, with values comparable with those for other activating mutations $\left(\mathrm{EC}_{50}\right.$ values for extracellular $\mathrm{Ca}^{2+}$ : wild-type, $4 \cdot 4 \mathrm{mM}$; E604K mutant, $3.6 \mathrm{mM}$ ) (Tan et al. 2003). To date, 25 activating mutations in the CaSR have been reported, and with the exception of a large deletion in the carboxyl-terminal tail, all are missense mutations (Hendy et al. 2000). Their location within the CaSR gene is variable as 14 are localized in the extracellular domain (Pollak et al. 1994, Baron et al. 1996, Pearce et al. 1996, De Luca et al. 1997, Mancilla et al. 1998, Okazaki et al. 1999, Conley et al. 2000, Hendy et al. 2000, Tan et al. 2003), six in the transmembrane helixes (Baron et al. 1996, De Luca et al. 1997, Watanabe et al. 1998a, Hendy et al. 2000) and two in the extracellular loops within the transmembrane domain (Baron et al. 1996, Hendy et al. 2000). Although some authors have pointed out that mutations in the transmembrane helixes might produce more severe hypocalcemia than those present in the extracellular domain (Watanabe et al. 1998b), no significant relationship has been further demonstrated between mutation location and penetrance of the mutation. The Glu ${ }^{604}$ Lys-activating mutation lies in the Cys-rich domain of the extracellular head, which seems to be required for the coupling of ligand binding to the activation of intracellular signaling pathways (Hu et al. 2000). The activating effect of $\mathrm{Glu}^{604}$ Lys might therefore arise from a sensitizing effect on signal transmission (Tan et al. 2003).

In order to explain the clinical differences between family members affected with the activating dominant mutation Glu ${ }^{604}$ Lys, polymorphisms of the PTH gene were also analyzed. Only two out of the three PTH polymorphisms were informative, showing that I.1, II.2 and II.3 were heterozygous for a nucleotide variation in both $B s t B \mathrm{I}$ and intron 1 polymorphisms. I.1 and II.3 were also carriers of the Glu ${ }^{604}$ Lys and those with major $\mathrm{ADH}$ penetrance. Although none of the BstBI and intron 1 polymorphisms have been associated with drastic effects on PTH expression or efficiency, translated as FIH presentation, both have been associated with differences in bone mineral density, bone dimension and osteoporosis (Almahroos et al. 1987, Gong et al. 1999, Hosoi et al. 1999, Gohda et al. 2002). I.1 and II.3, carrying both the CaSR mutation and the less favorable allelic form of each polymorphism, are likely to have their CaSRrelated condition worsened due to PTH deficiency. 
Thus, considering both the CaSR mutation and the polymorphic changes in the PTH gene, it might be speculated that the PTH gene acts as a modifier locus of the ADH condition. Further studies in kindreds presenting this activating mutation or other diseases related to mutations of the CaSR will be required to confirm this hypothesis.

\section{Acknowledgements}

We would like to thank Pelayo González for his support in the sequencing process and Diego García-Manso and Saleh Tuwaijri for supplying HEK-293 cells for the activation analysis. D A-H is a recipient of a Fundación para la Investigación Científica aplicada y la Tecnología scholarship. I S is a recipient of a Research Contract from Fondo de Investigaciones Sanitarias (FIS 00/3161).

\section{References}

Ahn TG, Antonarakis SE, Kronenberg HM, Igarashi T \& Levine MA 1986 Familial isolated hypoparathyroidism: a molecular genetic analysis of 8 families with 23 affected persons. Medicine 65 $73-81$.

Aida K, Koishi S, Tawata M \& Onaya T 1995 Molecular cloning of a putative $\mathrm{Ca}(2+)$-sensing receptor cDNA from human kidney. Biochemical and Biophysical Research Communications 214 524-529.

Almahroos GM, Docherty K, Fletcher JA, Webb T \& Heath DA 1987 Studies of the parathyroid hormone gene in normal subjects, and in subjects with primary hyperparathyroidism and familial benign hypercalcaemia. Fournal of Endocrinology 115 183-186.

Baron J, Winer KK, Yanovski JA, Cunningham AW, Laue L, Zimmerman D \& Cutler GB Jr 1996 Mutations in the $\mathrm{Ca}(2+)-$ sensing receptor gene cause autosomal dominant and sporadic hypoparathyroidism. Human Molecular Genetics 5 601-606.

Brauner-Osborne H, Jensen AA, Sheppard PO, O’Hara P \& Krogsgaard-Larsen P 1999 The agonist-binding domain of the calcium-sensing receptor is located at the amino-terminal domain. Journal of Biological Chemistry 274 18382-18386.

Brown EM 2000 G protein-coupled, extracellular Ca2+ $(\mathrm{Ca} 2+(\mathrm{o}))-$ sensing receptor enables $\mathrm{Ca} 2+(\mathrm{o})$ to function as a versatile extracellular first messenger. Cell Biochemistry and Biophysics 33 63-95.

Brown EM, Gamba G, Riccardi D, Lombardi M, Butters R, Kifor O, Sun A, Hediger MA, Lytton J \& Hebert SC 1993 Cloning and characterization of an extracellular $\mathrm{Ca}(2+)$-sensing receptor from bovine parathyroid. Nature 366 575-580.

Brown EM, Pollak M, Chou YH, Seidman CE, Seidman JG \& Hebert SC 1995a The cloning of extracellular $\mathrm{Ca}(2+)$-sensing receptors from parathyroid and kidney: molecular mechanisms of extracellular $\mathrm{Ca}(2+)$-sensing. Fournal of Nutrition 125 1965S-1970S.

Brown EM, Pollak M, Chou YH, Seidman CE, Seidman JG \& Hebert SC $1995 b$ Cloning and functional characterization of extracellular $\mathrm{Ca}(2+)$-sensing receptors from parathyroid and kidney. Bone 17 7S-11S.

Conley YP, Finegold DN, Peters DG, Cook JS, Oppenheim DS \& Ferrell RE 2000 Three novel activating mutations in the calcium-sensing receptor responsible for autosomal dominant hypocalcemia. Molecular Genetics and Metabolism 71 591-598.
De Campo C, Piscopello L, Noacco C, Da Col P, Englaro GC \& Benedetti A 1988 Primary familial hypoparathyroidism with an autosomal dominant mode of inheritance. Fournal of Endocrinological Investigation 11 91-96.

De Luca F, Ray K, Mancilla EE, Fan GF, Winer KK, Gore P, Spiegel AM \& Baron J 1997 Sporadic hypoparathyroidism caused by de novo gain-of-function mutations of the $\mathrm{Ca}(2+)$-sensing receptor. Fournal of Clinical Endocrinology and Metabolism $\mathbf{8 2}$ 2710-2715.

Ding C, Buckingham B \& Levine MA 2001 Familial isolated hypoparathyroidism caused by a mutation in the gene for the transcription factor GCMB. Fournal of Clinical Investigation 108 $1215-1220$.

Garrett JE, Capuano IV, Hammerland LG, Hung BC, Brown EM, Hebert SC, Nemeth EF \& Fuller F 1995 Molecular cloning and functional expression of human parathyroid calcium receptor cDNAs. Journal of Biological Chemistry 270 12919-12925.

Gohda T, Shou I, Fukui M, Funabiki K, Horikoshi S, Shirato I \& Tomino Y 2002 Parathyroid hormone gene polymorphism and secondary hyperparathyroidism in hemodialysis patients. American Fournal of Kidney Disease 39 1255-1260.

Gong G, Johnson ML, Barger-Lux MJ \& Heaney RP 1999 Association of bone dimensions with a parathyroid hormone gene polymorphism in women. Osteoporosis International 9 307-311.

Hendy GN, D'Souza-Li L, Yang B, Canaff L \& Cole DE 2000 Mutations of the calcium-sensing receptor (CASR) in familial hypocalciuric hypercalcemia, neonatal severe hyperparathyroidism, and autosomal dominant hypocalcemia. Human Mutations 16 281-296.

Hosoi T, Miyao M, Inoue S, Hoshino S, Shiraki M, Orimo H \& Ouchi Y 1999 Association study of parathyroid hormone gene polymorphism and bone mineral density in Japanese postmenopausal women. Calcified Tissue International 64 205-208.

Hu J, Hauache O \& Spiegel AM 2000 Human Ca2+ receptor cysteine-rich domain. Analysis of function of mutant and chimeric receptors. Fournal of Biological Chemistry 275 16382-16389.

Kanazawa H, Tanaka H, Kodama S, Moriwake A, Kobayashi M \& Seino Y 2000 The effect of calcium-sensing receptor gene polymorphisms on serum calcium levels: a familial hypocalciuric hypercalcemia family without mutation in the calcium-sensing receptor gene. Endocrine Fournal 47 29-35.

Katsumata K, Nishizawa K, Unno A, Fujita Y \& Tokita A 2002 Association of gene polymorphisms and bone density in Japanese girls. Fournal of Bone Mineral Metabolism 20 164-169.

Mancilla EE, De Luca F \& Baron J 1998 Activating mutations of the Ca2+-sensing receptor. Molecular Genetics and Metabolism 64 198-204.

Miric A \& Levine MA 1992 Analysis of the preproPTH gene by denaturing gradient gel electrophoresis in familial isolated hypoparathyroidism. Fournal of Clinical Endocrinology and Metabolism 74 509-516.

Mullersman JE, Shields JJ \& Saha BK 1992 Characterization of two novel polymorphisms at the human parathyroid hormone gene locus. Human Genetics 88 589-592.

Nagase T, Murakami T, Tsukada T, Kitamura R, Chikatsu N, Takeo H, Takata N, Yasuda H, Fukumoto S, Tanaka Y, Nagata N, Yamaguchi K, Akatsu T \& Yamamoto M 2002 A family of autosomal dominant hypocalcemia with a positive correlation between serum calcium and magnesium: identification of a novel gain of function mutation (Ser(820)Phe) in the calcium-sensing receptor. Fournal of Clinical Endocrinology and Metabolism $\mathbf{8 7}$ 2681-2687.

Okazaki R, Chikatsu N, Nakatsu M, Takeuchi Y, Ajima M, Miki J, Fujita T, Arai M, Totsuka Y, Tanaka K \& Fukumoto S 1999 A novel activating mutation in calcium-sensing receptor gene 
associated with a family of autosomal dominant hypocalcemia. Fournal of Clinical Endocrinology and Metabolism 84 363-366.

Parkinson DB, Shaw NJ, Himsworth RL \& Thakker RV 1993 Parathyroid hormone gene analysis in autosomal hypoparathyroidism using an intragenic tetranucleotide (AAAT)n polymorphism. Human Genetics 91 281-284.

Pearce SH, Williamson C, Kifor O, Bai M, Coulthard MG, Davies M, Lewis-Barned N, McCredie D, Powell H, Kendall-Taylor P, Brown EM \& Thakker RV 1996 A familial syndrome of hypocalcemia with hypercalciuria due to mutations in the calcium-sensing receptor. New England Fournal of Medicine 335 1115-1122.

Pollak MR, Brown EM, Chou YH, Hebert SC, Marx SJ, Steinmann B, Levi T, Seidman CE \& Seidman JG 1993 Mutations in the human $\mathrm{Ca}(2+)$-sensing receptor gene cause familial hypocalciuric hypercalcemia and neonatal severe hyperparathyroidism. Cell $\mathbf{7 5}$ 1297-1303.

Pollak MR, Brown EM, Estep HL, McLaine PN, Kifor O, Park J, Hebert SC, Seidman CE \& Seidman JG 1994 Autosomal dominant hypocalcaemia caused by a $\mathrm{Ca}(2+)$-sensing receptor gene mutation. Nature Genetics 8 303-307.

Sambrook J, Fritsch EF \& Maniatis T 1989 Molecular Cloning: A Laboratory Manual, edn 2. Cold Spring Harbor: Cold Spring Harbor Laboratory Press.

Sunthornthepvarakul T, Churesigaew S \& Ngowngarmratana S 1999 A novel mutation of the signal peptide of the preproparathyroid hormone gene associated with autosomal recessive familial isolated hypoparathyroidism. Fournal of Clinical Endocrinology and Metabolism 84 3792-3796.

Tan YM, Cardinal J, Franks AH, Mun HC, Lewis N, Harris LB, Prins JB \& Conigrave AD 2003 Autosomal dominant hypocalcemia: a novel activating mutation (E604K) in the cysteine-rich domain of the calcium-sensing receptor. Fournal of Clinical Endocrinology and Metabolism 88 605-610.

Watanabe T, Bai M, Lane CR, Matsumoto S, Minamitani K, Minagawa M, Niimi H, Brown EM \& Yasuda T $1998 a$ Familial hypoparathyroidism: identification of a novel gain of function mutation in transmembrane domain 5 of the calcium-sensing receptor. Fournal of Clinical Endocrinology and Metabolism $\mathbf{8 3}$ 2497-2502.

Watanabe T, Mochizuki H, Kohda N, Minamitani K, Minagawa M, Yasuda T \& Niimi H 1998b Autosomal dominant familial hypoparathyroidism and sensorineural deafness without renal dysplasia. European Fournal of Endocrinology 139 631-634.

Winter WE, Silverstein JH, Maclaren NK, Riley WJ \& Chiaro JJ 1983 Autosomal dominant hypoparathyroidism with variable, age-dependent severity. Fournal of Pediatrics 103 387-390.

Yamamoto T, Yoshimasa Y, Koshiyama H, Sugiyama K, Okigaki M, Yamada T, Ishii H, Yagura T, Fujimoto K, Ohnishi T, Koh T, Hino M, Kurahachi H, Yoshimasa T \& Nakao K 1997 Lack of mutations of preproparathyroid hormone gene in three kindreds with familial isolated hypoparathyroidism. Endocrine fournal 44 175-180.

Zhang Z, Sun S, Quinn SJ, Brown EM \& Bai M 2001 The extracellular calcium-sensing receptor dimerizes through multiple types of intermolecular interactions. Fournal of Biological Chemistry 276 5316-5322.

Received 6 May 2003

Accepted 5 June 2003

Made available as an

Accepted preprint on 6 June 2003 